\title{
Dilated eye exam
}

National Diabetes Information Clearinghouse (NDIC)

\section{Source}

National Diabetes Information Clearinghouse (U.S.). (2009). The diabetes dictionary. [Bethesda, Md.]: U.S. Dept. of Health and Human Services, National Institutes of Health, National Institute of Diabetes and Digestive and Kidney Diseases, National Diabetes Information Clearinghouse.

A test done by an eye care specialist in which the pupil—the black center-of the eye is temporarily enlarged with eyedrops to allow the specialist to see the inside of the eye more easily.

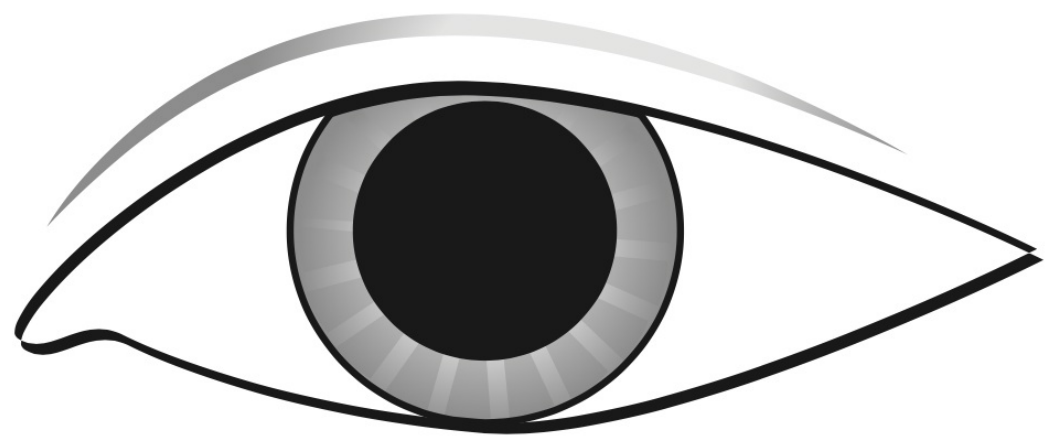

Dilated eye

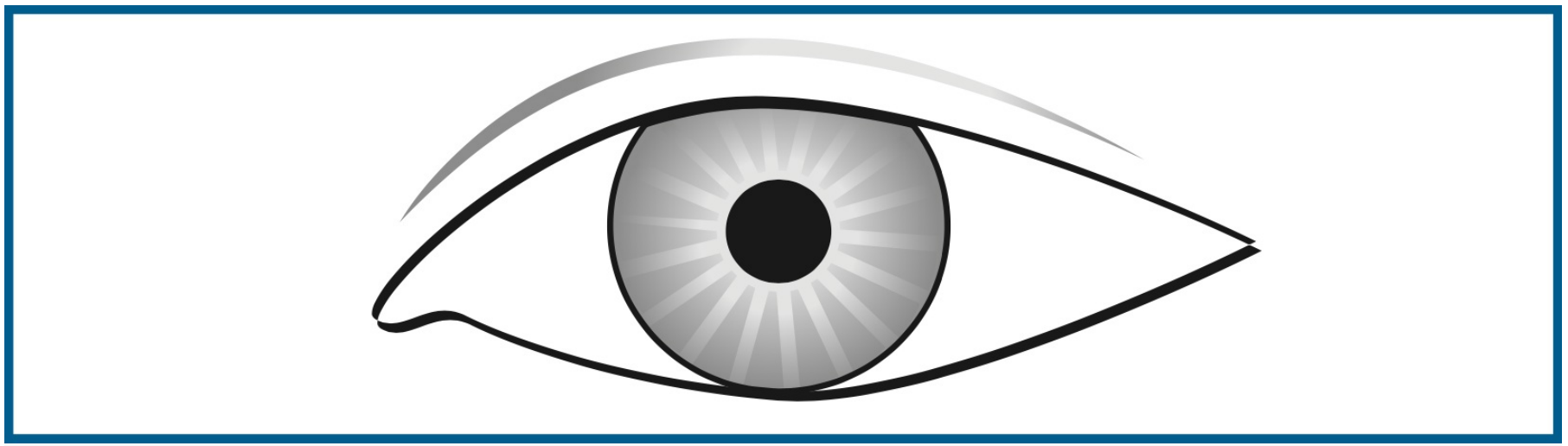

Undilated eye 